\title{
Psicopatologia dos transtornos alimentares e seus estados melancólicos
}

\author{
Flávia Lana Garcia de Oliveira*1 \\ Tania Coelho dos Santos*2
}

A correlação entre estados melancólicos e a psicopatologia dos transtornos alimentares foi observada desde os primórdios da psicanálise e continua a ser verificada nos dias de hoje. Para atualizar a pesquisa sobre as consequências da posição melancólica na clínica das anorexias, bulimias e obesidades, revisitamos a metapsicologia da relação de objeto desses estados psicopatológicos. Acreditamos que ela pode contribuir para elucidar uma possível constante fantasmática nas configurações sintomáticas anoréxicas, bulímicas e obesas.

Palavras-chave: Fantasma, melancolia, anorexia, bulimia, obesidade

*1 Doutoranda da Universidade Federal do Rio de Janeiro - UFRJ (Rio de Janeiro, $\mathrm{RJ}, \mathrm{Br})$.

${ }^{* 2}$ Universidade Federal do Rio de Janeiro - UFRJ (Rio de Janeiro, RJ, Br). 


\section{A posição melancólica como um elemento clínico transestrutural}

A interface entre a melancolia e os transtornos alimentares foi observada desde o início da obra freudiana e vem perpassando também as considerações de muitos psicanalistas na atualidade. Freud (1895/1996b) fez alusões à presença da recusa anoréxica do comer que permitem articulá-la à posição melancólica. É ainda nos primórdios da psicanálise que se refere à anorexia como uma "neurose alimentar paralela à melancolia" (p. 247), ou como "uma melancolia em que a sexualidade ainda não se desenvolveu" (p. 247). Freud também destacou que, nesse quadro, "a paciente afirma que não se alimenta simplesmente porque não tem nenhum apetite; não há qualquer outro motivo. Perda do apetite — em termos sexuais, perda da libido" (p. 247). Devido à associação da imensa maioria de casos envolvendo anorexias, bulimias e obesidades a inclinações depressivas, é relevante considerar se essas depressões são melancólicas ou neuróticas. O estado melancoliforme perpassa em graus distintos uma grande diversidade de sujeitos cujo principal sintoma é um transtorno alimentar, muito mais como uma posição frente à realidade, sem que necessariamente se configure uma melancolia propriamente dita, aquela situada no campo da ausência da função organizadora do Nome-do-Pai.

Alguns autores tendem a ultrapassar rapidamente o valor explicativo da vertente edipiana e histérica nesses casos, aproximando-os das chamadas patologias narcísicas. Na medida em que apostam depressa demais em um novo uso do corpo a ser elucidado e em uma nova funcionalidade do sintoma, correm o risco de esvaziar a importância do papel do inconsciente, do fantasma e da função fálica na constituição subjetiva desses pacientes. Na 


\section{ARTIGOS}

orientação lacaniana, o diagnóstico diferencial dos transtornos alimentares reduzido à diferença entre histeria e melancolia tende a reduzir a descrição, a construção e a interpretação destes quadros clínicos à mera distinção clássica entre neurose e psicose. Esta abordagem nos parece insuficiente para caracterizá-las. Preferimos não seguir esse fio lógico, pois acreditamos que é preciso renovar a abordagem desse território psicopatológico. Discordamos da insistência numa clínica diferencial entre histeria e melancolia porque tende a conceder muita importância à oposição entre recalcamento do erotismo oral e narcisismo mortífero que não considera a posição melancólica enquanto um sintoma transestrutural. Nossa aposta é a de que é possível fazer um bom uso da configuração fantasmática que promove esses modos de gozo a serviço de resultados terapêuticos mais efetivos. Retomar a metapsicologia da melancolia exige uma revisão mais original da transmissão freudiana que possa recolher os elementos fantasmáticos que se repetem numa diversidade de indivíduos que não são psicóticos.

Coelho dos Santos (2008) recorda o que muitas vezes foi destacado pelo psicanalista Jacques-Alain Miller: atualmente, no campo das neuroses, os sintomas são menos alimentados pelo sentido. Analogamente, as psicoses nos dias de hoje são menos delirantes. Por isso, a dúvida diagnóstica é uma constante na prática atual. As modalidades de adoecimento psíquico que gradualmente se tornam dominantes evidenciam satisfações pulsionais que não se mascaram pelo recalque. Pelo contrário, dispensam o simbólico e se manifestam como fantasmas a céu aberto. A melancolia parece ser uma ferramenta promissora de pesquisa acerca das psicopatologias relacionadas à dietética (os chamados novos sintomas), ou seja, o modo pelo qual o gozo é regulado na contemporaneidade, por habitar uma espécie de "limbo diagnóstico" atrelado a alterações na esfera narcísica. Mesmo sendo considerada por muitos lacanianos como uma das manifestações da foraclusão do Nome-do-Pai, a melancolia não se insere no continuum das psicoses de modo simples: há estados melancólicos sem delírios, períodos melancólicos sem prolongamento maníaco, assim como tempos de razoável estabilidade psíquica: o eu não parece dilacerado ou superinvestido como na esquizofrenia ou na paranoia (Coelho dos Santos \& Oliveira, 2012, mar.). Essa difícil classificação em comparação às demais psicoses levou Freud (1924/1996e) a forjar a categoria "neurose narcísica" para designá-la. Ainda que inserida na vizinhança das neuroses, a resposta melancólica é formalizada na obra freudiana como fruto do conflito entre o eu e o supereu, diferentemente das neuroses transferenciais, que são o resultado da tensão entre o eu e o isso, bem como 


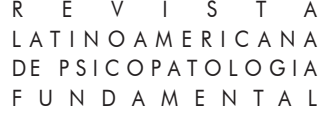

das psicoses tradicionais, resultantes da perturbação das relações entre o eu e os ideais no mundo externo.

Mais uma observação que vale ser ressaltada antes de explorarmos os conceitos metapsicológicos que integram a abordagem da melancolia. Lembramos que, em 2004, na Convenção de Antibes, Miller recorre aos estudos psicopatológicos do fenomenólogo alemão Hubertus Tellenbach a fim de incluir a melancolia no rol das psicoses ordinárias - psicoses designadas por ele como as do tempo em que o Outro não existe. Tellenbach aborda o typus melancholicus como uma categoria tipológica na qual predomina a "hipernormalidade". Seu traço essencial seria a tendência a uma forte ordenação, à hipertrofia da consciência do dever, à escrupulosidade nas relações profissionais, interpessoais, nas tarefas diárias e consigo mesmo, sem que nada disso preencha de sentido a vida do indivíduo. Essas atividades assumem valor existencial, porém são meramente normativas, não estando vinculadas ao ideal do eu.

Para além do debate sobre se a melancolia seria uma estrutura à parte ou um subtipo de psicose, sua afinidade com a psicose ordinária - graças à presença da sobreidentificação à norma enquanto uma solução sintomá250 tica para tratar a falência fálica - talvez contribua para fundamentar nossa suposição de que a psicopatologia contemporânea revela que também uma grande diversidade de indivíduos é habitado por um laço muito pouco dialético com um Outro social enfraquecido em sua potência simbólica. Esta, entre outras razões, levaram Coelho dos Santos (2016, dez.) a questionar a tese de Miller (2005) acerca da inexistência do Outro na contemporaneidade. Argumenta em favor de sua posição que as versões do Outro apresentam-se de forma muito mais maciça - pode-se dizer que o Outro existe até demais - nas patologias em que seu instrumento regulador, a função fálica, está enfraquecida. Tellenbach descreve precisamente - revelando a influência estritamente freudiana - os distúrbios de identificação do melancólico ou do pré-melancólico enquanto resultantes da identificação narcísica ao objeto amado. Tal mecanismo pode ser constatado pela presença de um sentimento de "comunidade simbiótica" com o outro (Miller et al., 2004). É preciso situar qual é a perturbação do narcisismo em jogo e quais os impasses no processo de constituição do corpo, do eu e da relação de objeto nessa afecção. Pretendemos conectar essas articulações por meio de uma apreensão mais abrangente e precisa dos distúrbios alimentares, elucidando o estatuto do fantasma nessas configurações em que o gozo corporal transborda os limites da função fálica, sem que necessariamente se trate de uma psicose. 


\section{ARTIGOS}

\section{O que sabemos sobre o fantasma do melancólico?}

Em "Luto e melancolia", Freud (1917/2010b) explica o sofrimento psíquico melancólico a partir do afeto normal de luto. Se Freud justifica inicialmente a comparação entre o luto e a melancolia pela diferença entre duas respostas à realidade da perda do objeto amado, vai mostrando, contudo, que as semelhanças entre o enlutado e o melancólico são muito mais fenomenológicas do que estruturais. Na melancolia, a perda refere-se especialmente à admiração, à crença ou a alguém que encarnava o ideal. Desapontado com a pessoa cuja função deveria ser a de protegê-lo, estimulá-lo e orientá-lo em direção ao futuro, o melancólico não se desprende do objeto outrora amado, mas o devora e torna-se idêntico a ele. Como o objeto não é mais admirado, é a sombra de um objeto decepcionante que recai sobre o eu. $\mathrm{O}$ eu se torna empobrecido pela identificação a um objeto sem valor. Por este motivo, o aspecto diferencial que distingue a melancolia do luto é a deterioração da autoestima. Luto e melancolia são soluções radicalmente distintas no que se refere ao modo pelo qual o eu lida com a ausência de um objeto fortemente investido na economia psíquica.

De acordo com a teoria freudiana, a boa constituição do eu depende de que a perda do objeto incestuoso seja compensada pelo advento da identificação ao ideal pós-edípico veiculado pela transmissão paterna. Freud (1915/2010a) caracteriza esse primeiro funcionamento a ser ultrapassado como o da incorporação ou devoração do objeto no registro da pulsão oral, no qual predomina "um tipo de amor que é compatível com a abolição da existência separada do objeto e que, portanto, pode ser descrito como ambivalente" (p. 143). A libido ligada ao objeto perdido pode, então, se desprender da figura materna e refluir para o eu, colorida pela promessa de novos encontros depois da puberdade. $\mathrm{O}$ trabalho de luto define, justamente, a mobilização da balança libidinal rumo à retirada das conexões com esse objeto, o que ocorre simultaneamente a um superinvestimento do mesmo. Essa é a condição para que o eu venha a alcançar uma nova posição libidinal. Com essa renúncia, escapa-se da absorção maciça pelo objeto. Embora nesse texto Freud não tenha examinado o papel do aparato edipiano e do complexo de castração no trabalho de luto, sabemos que é do destino dessa trajetória que depende a subjetivação da perda de um objeto que esgote a satisfação pulsional. Trata-se, aí, do luto fundamental que culmina na separação do objeto primordial de satisfação no laço com a figura materna. O recalque primário instaura um núcleo inabordável pela significação, relativo ao 


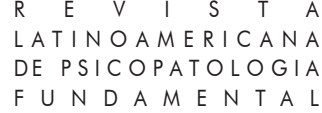

encontro com o objeto perdido - a mãe. Perder o objeto é ganhar a possibilidade de significá-lo.

$\mathrm{Na}$ decepção melancólica, não se trata da exigência universal da separação do primeiro objeto amoroso. O rompimento defeituoso do laço com o objeto desencadeia na vida psíquica um delírio de pequenez capaz de comprometer as atividades de autoconservação como o sono e os hábitos alimentares (Freud, 1917/2010b). Freud vincula a origem da autorrecriminação melancólica à hostilidade que originalmente foi dirigida ao objeto. Essa resposta sucede um tempo anterior de ligação ao objeto amado, a qual foi fortemente fragilizada devido a um irreversível desapontamento. A posição masoquista do melancólico estaria intimamente associada às tendências sádicas que eclodem a partir dessa decepção e não dão lugar à experiência normal de perda e luto. Ao contrário, retornam sobre o próprio eu. Trata-se do avesso da paixão narcísica, segundo Coelho dos Santos \& Sartori (2007). Outro aspecto do funcionamento melancólico permite desvelar o lugar do Outro nesse quadro: embora o paciente desfira severos insultos contra si mesmo e até demonstre sentir pena de seus familiares por estarem ligados a alguém tão indigno que mereceria punição e castigo, curiosamente, 252 o melancólico não é alguém envergonhado, humilde ou submisso. Freud (1917/2010b) enfatiza o traço oposto, o de "uma insistente comunicabilidade que acha satisfação no desnudamento de si próprio" (p. 177). A obscenidade da exibição da própria condição ocupa a cena, sem as barreiras do pudor. Isso porque sua conduta é guiada por uma experiência interna de despeito, "real ofensa" ou "decepção" (p. 180). O Outro do melancólico é aquele acusado de não lhe ter devotado seu desejo suficientemente.

$\mathrm{Na}$ melancolia, a experiência da perda é inesgotável e dilacerante. $\mathrm{O}$ mundo torna-se esvaziado libidinalmente, desafetado, desprovido de significações vitalizantes. Nenhum objeto assume valor fálico e é revestido de brilho. Porém, como veremos em seguida, o Outro do melancólico não é pleno, mas deveria ser. No plano fantasmático, o melancólico revela um profundo ressentimento na relação com o Outro e uma forte indignação face à castração deste, pois em lugar da marca do desejo no Outro, o que se apresenta para ele seria sua hipossuficiência. Freud nomeia esse elemento como uma posição de revolta: os melancólicos sentem-se ofendidos, "como se lhes tivesse sido feita uma grande injustiça" (p. 180). Lambotte (1997) sublinha que o desenlace melancólico é precedido por uma reivindicação agressiva endereçada ao mundo exterior. Como não alcança a satisfação esperada, a reivindicação transforma-se no fatalismo e na descrença que marcam a escolha de 


\section{ARTIGOS}

gozo nessa estrutura. Como se pode ver, essa é uma interpretação específica da falta do Outro (castração) sem a elaboração proporcionada pela dimensão do sexual. Não seria essa uma interpretação ratificada e coordenada pelo discurso social neodemocrático que proclama a universalidade dos direitos do indivíduo - independentemente de que ele faça qualquer coisa para assegurá-los — com o agravante da sujeição à lógica do mercado? Não reconhecemos nessa posição, o consumidor insatisfeito, lesado em seus direitos essenciais e absolutos e que cobra do Outro o gozo que lhe é devido, tal como é difundido por esse discurso?

Encontramos em Freud (1917/2010b) o desenvolvimento de alguns argumentos que dão mais estofo a essa perspectiva. Na melancolia, o laço com o mundo externo cede lugar a outra modalidade de relação, denominada por ele como identificação narcísica, o que situa o estatuto do Outro no campo fantasmático do melancólico: "O eu quer incorporar esse objeto e para tal, em conformidade com a fase oral, ou canibalística, do desenvolvimento da libido, deseja devorá-lo" (p. 182). Um funcionamento psíquico dominado pela avidez, absorvido na vertente oral da pulsão, no qual reina um modo de relação canibalesco, se instala nesse caso. Trata-se também de um modo de se relacionar com o Outro devorando-o e oferecendo-se para ser devorado por ele. O laço com o objeto resta fixado num tipo de satisfação apropriada ao período de indiferenciação entre o sujeito e o Outro e que prescinde da renúncia libidinal necessária para renovar o investimento na via sexuada: "refugiando-se no eu, o amor escapa à eliminação" (p. 192). Na melancolia, há uma anestesia [sexual] psíquica, de um lado, e, de outro, um "grande anseio pelo amor em sua forma psíquica" (Freud, 1894/1996a, p. 237). Indagamos se esse amor — que não admite separação, fora do sentido sexual —, não seria a própria definição metapsicológica da reivindicação do direito ao gozo de consumir, forma atual da lei do mercado. A falha aqui é experimentada como puro obstáculo ao gozo do consumo a que todo sujeito tem um direito absoluto em seu laço com um Outro reduzido à mercadoria a serviço da satisfação pulsional. Freud enfatiza que esse engessamento pulsional coincide com a ambivalência da organização sádico-anal, atualizada como impulso de se apoderar do objeto, indiferente à consequência de danificá-lo ou aniquilá-lo.

Em lugar de um sujeito dividido, sacrificado pelo consentimento à perda do objeto e, por isso mesmo, apaziguado em seu gozo pelo amor ao Outro graças à transmissão fálica, tal modalidade de aprisionamento na referência oral-canibalesca ao Outro alastra um descontentamento, uma posição de consumidor insatisfeito com os limites da fruição do gozo. Freud 


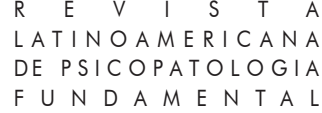

(1940b/1996h) revisita a questão da indiferenciação eu-outro em jogo no uso do objeto ao nível da pulsão oral. Recorda que inicialmente a criança não distingue o seio e seu próprio corpo e que esse destacamento do objeto só se instaura quando ele se revela ausente. Surge em seu lugar a conexão ao Outro materno como tal. Portanto, a primeira aparição do Outro é completamente objetalizada. Esse tipo de laço primitivo se mantém no funcionamento melancólico.

Aplicamos em nossa abordagem do problema dos transtornos alimentares contemporâneos, a tese de Coelho dos Santos (2016, dez.) de que esse tipo de laço se generalizou, uma vez garantido pelo discurso e pelas práticas desenvolvidas sob o império da Lei do mercado. A autora argumenta que o grande Outro primitivo, a Coisa (Das Ding) não sofre mais, necessariamente, os efeitos do recalque primário como consequência da universalização da lei da castração (recalque secundário). Sustenta portanto, como hipótese, que o recalque primário, quando a Coisa (Das Ding) é rebaixada à forma geral da mercadoria (objeto mais-de-gozar), coordena-se ao desmentido da castração, eternizando o vínculo oral primitivo com o Outro, agora assegurado pela universalização da lei do mercado. O Outro não se constitui marcado pela

254 falta, condição do advento do desejo. O Outro constitui-se como "cultura pura de pulsão de morte" (Freud, 1923a/1996c, p. 66), apresentando-se como um supereu que incita ao gozo pulsional desmedido. Esta lógica pulsional do "quanto mais, mais ainda", é potencialmente destrutiva, pois desmente que o gozo absoluto é impossível. Coelho dos Santos (2016, dez.) defende que a revolta, afeto que marca os movimentos sociais depois de 1968, expõe o sujeito a um tipo de insatisfação mais radical que a insatisfação histérica e potencialmente autodestrutiva.

\section{A posição melancólica como a lógica fantasmática do consumidor}

O que nos interessa agora é mostrar que a melancolia é uma posição que se transmite. Trata-se de uma perturbação nas relações primitivas entre o sujeito e o Outro, onde a natureza do Outro desempenha um papel essencial. Lambotte (1997) articula a gênese da melancolia a um tempo pré-especular em que foi impossível forjar uma imagem unificada de si, em consequência de um não desejo do Outro materno. Essa falha é um entrave para a "nova ação psíquica" formadora do narcisismo. A indiferença ou o fechamento numa posição apática assumida pelo Outro materno em relação ao sujeito impede 


\section{ARTIGOS}

que este advenha imaginariamente. Em decorrência disso, para o melancólico, torna-se difícil sentir-se como corpo e apoderar-se do valor significante de um reflexo que não pertence a ninguém.

Esses sujeitos são acompanhados pela absoluta certeza de terem sofrido falhas de criação, de terem sido feridos, ou de terem sido abandonados. $\mathrm{O}$ investimento amoroso da mãe é questionado e a criança nunca alcança o rígido ideal exigido. A perda figura-se como inexaurível. A esse respeito, Berlinck (2009) destaca que o bebê, enquanto produção narcísica, deve ser desalojado da redoma ideal absoluta quando se torna real. Apenas essa interferência pode engendrar uma nova dinâmica em que, "visto como um ideal rejeitado, cria-se a condição no bebê de ter um ideal" (p. 3). Em uma recente conferência, Dufour (2016) observa que muitos sujeitos pós-modernos são marcados pelo sentimento de serem órfãos do Outro. Nessa nova subjetividade, uma "melancolia latente" pertenceria ao mesmo rol de fenômenos, tais como a impossibilidade de falar em primeira pessoa, a ilusão de onipotência e a fuga pelos falsos self, como manobras de maciça evitação da falha do Outro.

Paradoxalmente, a onipotência materna ronda o fantasma melancólico e comparece extensamente em situações de sujeitos obesos, anoréxicos e bulímicos. A mãe é percebida como dotada de um poder hiperdestrutivo e caprichoso. A imagem materna adquire uma importância exacerbada, numa relação pouco dialética, impregnada por oposições que remetem a tensões narcísicas mortíferas: "ou ela ou eu"; "ou o ideal ou a morte"; "ou tudo ou nada". O abalo narcísico desse lugar ideal que o Outro ocupava leva à dissolução imaginária e o sujeito se vê lançado na identificação com o objeto abandonado pelo Outro. A identificação ao objeto $a$ produz a tirania do supereu materno alinhado ao excesso pulsional.

Em lugar da instalação da lei da castração, reguladora da pulsão por meio do desejo, encontramos a onipotência da mãe fálica e o desmentido da castração da mãe. O tema do desmentido evidencia uma chave de leitura importante para a abordagem de casos clínicos atravessados pela incerteza diagnóstica (Camargo \& Coelho dos Santos, 2012). Sabemos que Freud estende a hipótese do desmentido (Verleugnung) para as neuroses, as quais se diferenciariam das perversões e das psicoses pelo primado da atitude psíquica coerente com a realidade, a qual impõe a penosa descoberta de que a mãe não tem o pênis. A outra atitude, mais afinada com as exigências pulsionais, mantém a mãe fálica (Freud, 1940a/1996g). O recalque seria o antídoto contra o recrudescimento dessa segunda tendência. A ausência do pênis materno é traumática porque afeta o narcisismo da criança (Freud, 1923b/1996d; 


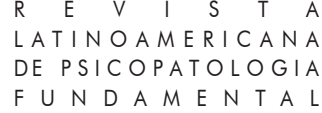

1927/1996f). O conflito inerente às neuroses é presidido precisamente pela reivindicação de um reparo ao dano narcísico causado pelo consentimento às constrições impostas pela realidade. A neurose é prova de que a realidade nunca é totalmente exitosa em domesticar as pulsões. O recalque sempre fracassa e a outra face do ego é forte aliada da posição de objeto. Ela só pode ser contrabalanceada pela ação efetiva da autoridade paterna, que é internalizada como a instância psíquica do supereu pós-edipiano.

Encontramos no texto freudiano o argumento de que é a função do pai que fundamentalmente é desmentida. Freud circunscreve a presença simultânea de duas crenças mutuamente incompatíveis: "a mulher ainda tem um pênis" e "meu pai castrou a mulher" (Freud, 1927/1996f, p. 159). O enfraquecimento do prestígio da hierarquia geracional promovido pela discursividade atual, que é norteada pelo descrédito das proibições reguladoras e pelo incentivo incessante do gozo, difunde um desmentido banal da autoridade simbólica. Retornamos à tese defendida por Coelho dos Santos (2016, dez.) para situar o que se passa com o sujeito contemporâneo. Seguindo a lógica proposta por Freud, na medida em que a realidade não veicula da mesma maneira essa função guardiã do recalque, instaura-se a radicalização da reivindicação de uma compensação à ferida narcísica.

O desprezo pela inexistência do pênis na mãe é correlato à desqualificação da função do pai, cujo exercício de autoridade comparece no psiquismo inicialmente sob a ameaça imaginária da castração do pênis. Posteriormente, ao comentar como o desmentido da castração materna levava um menino a insistir no ato masturbatório, a despeito das proibições que incidiam sobre ele, Freud (1940a/1996g) designa essa maneira de lidar com a realidade como "audaciosa" e "indiferente" à intervenção do pai. O avesso disso é um acirrado temor da devoração pelo Outro que "pela ajuda da regressão à fase oral, assumia a forma de um medo de ser comido pelo pai” (p. 295). Portanto, o desmentido da autoridade simbólica exacerba a experiência da falta do Outro como algo insuportável, como puro trauma que não dá acesso à elaboração sexual do desejo. Prevalece o fantasma de um dano narcísico irremediável, o que pode conduzir, em alguns casos, ao estado melancoliforme. O desmentido do Outro simbólico associa-se à proliferação da posição do consumidor insatisfeito que busca uma contrapartida de gozo. Subjaz a crença de um Outro ilimitado, que pode tudo. A lógica do mercado sabe bem servir-se dessa ficção oferecendo-se como o Outro que pode prover objetos de satisfação para "todos os gozos". Isso repercute: na experiência de violência do laço ao Outro como devoração pulsional. 


\section{ARTIGOS}

Como contrapartida, ao Outro nada pode faltar. Este nos parece ser outro componente perverso intrínseco às neuroses do contemporâneo: o sujeito se oferece como o objeto que pode tamponar a falta do Outro. Lacan assinala que: "o perverso é aquele que se consagra a tapar o buraco do Outro. Para introduzir aqui as cores que dão relevo às coisas, direi que, até certo ponto, ele está do lado do fato de que o Outro existe. É um defensor da fé" (Lacan, 1968-1969/2008, p. 245). No contemporâneo, com a claudicação do recalque, a significação fálica ou a dialética entre ser ou não ser o falo, não instala a consideração pelas limitações inevitáveis que a realidade coloca, levando o sujeito a tentar preservar o Outro hiperconsistente a todo custo.

A fim de depurar o elemento fantasmático em jogo na onipotência do Outro materno, retornamos à distinção entre as modalidades de resposta à perda do objeto: privação, frustração e castração. Neste ponto, o registro da frustração atrai nossa atenção por algumas razões. Primeiramente, por esclarecer como se dá a passagem que inaugura a entrada do Outro materno no circuito libidinal da criança. A dialética da frustração implica um dano imaginário, pois se estabelece como um "conjunto de impressões reais" (Lacan, 1956-1957/1995, p. 36), no qual a mãe, até então simbólica e detentora dos objetos reais, a partir do momento em que não responde, torna-se real. Já os objetos, antes reduzidos a objetos de satisfação, ganham estatuto simbólico de dom do amor. A anorexia costuma ser situada como uma estratégia frente à fragilização desse processo. O objeto nada é forjado como signo de amor do qual o objeto real é despojado, numa espécie de forçamento da presentificação de uma ausência (Barbosa, 2010, dez.). Mediante um Outro que se abstém quanto ao seu desejo, a recusa anoréxica visaria, ainda que de modo simbolicamente empobrecido, restituir a dimensão desejante. A falta materna é tomada muito mais no âmbito de um abandono, onde não ser tudo equivaleria a ser nada.

Quando o sujeito não se separou do Outro por meio da mediação fálica, a separação é experimentada como abandono por uma mãe para quem seu bebê não representa o objeto que vem suprir aquilo que falta a ela. Não ser o que falta ao Outro expõe o sujeito aos efeitos da pulsão de morte, sem atenuação, por meio de manifestações maciças de gozo. Ao contrário de um apelo simbólico através da eleição de um objeto fóbico para estancar uma experiência de gozo avassaladora, o corpo seria abandonado ao capricho de um supereu materno, constituído como imperativo de gozo.

Os modos de satisfação oral observados na anorexia, na bulimia e na obesidade emergem quando a castração do Outro materno é desmentida. Sem contarem com o suporte do significante fálico, esses pacientes buscam retroagir a um tempo que nunca existiu na realidade, forjando um estado mítico de 


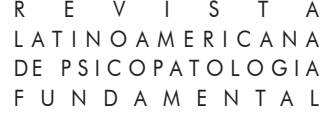

indiferenciação com o Outro na relação autoerótica como seio. O fantasma de completude e indiferenciação com o Outro materno é uma formação psíquica destinada a desmentir o fato de nunca ter sido para o Outro, aquilo que the falta. Esse Outro é reduzido a uma mercadoria da qual se necessita mais do que tudo. Essencialmente porque nunca esteve à altura de simbolizar o lugar de um desejo autêntico. Essa avidez devoradora pelo Outro coordena-se à voracidade capitalista pelo lucro. De acordo com Marret (2010), o fantasma deve ser o efeito de uma ação do semblante paterno que civiliza o gozo. Um fantasma sem a função fálica é desorganizador, pois veicula a angústia de ser devorado de um sujeito sem que seu valor seja ao mesmo tempo libidinizado.

\section{Referências}

Barbosa, D. S. (2010, dez.). Anorexia mental como resistência à onipotência materna. Ágora, $\operatorname{VIII}(2), 229-242$.

Berlinck, M. T. (2009). As bases do amor materno, fundamento da melancolia. $6^{o}$ Congresso Norte-Nordeste de Psicologia, Belém, PA, maio/2009.

Camargo, S., \& Coelho dos Santos, T. (2012). O Homem dos lobos e a atualidade da incerteza diagnóstica. Tempo Psicanalítico, 2(44), 13-33.

Coelho dos Santos, T., \& Sartori, A. P. (2007). Loucos de amor! Neuroses narcísicas, melancolia e erotomania feminina. Tempo Psicanalítico, 1(39), 13-33.

Coelho dos Santos, T. (2008). Sobre os finais de análise: sexuação e invenção. Tempo Psicanalítico, 1(40), 105-120.

Coelho dos Santos, T. (2016, dez.). O Outro que não existe: verdade verídica, verdades mentirosas e desmentidos veementes. Ágora, 19(3), 565-604.

Coelho dos Santos, T., \& Oliveira, F. L. G. (2012, mar.). Teoria e clínica psicanalítica da psicose em Freud e Lacan. Psicologia em Estudo, 1(17), 73-82.

Dufour, D.-R. (2016). L'Autre lacanien, une raison dans le réel. VI Simpósio do Instituto Sephora de Ensino e Pesquisa de Orientação Lacaniana, Rio de Janeiro, RJ, out. 2016.

Freud, S. (1996a). Rascunho E: Como se origina a angústia. In Edição Standard Brasileira das Obras Psicológicas Completas de Sigmund Freud (pp. 235-241). Rio de Janeiro: Imago. (Trabalho original publicado em 1894).

Freud, S. (1996b). Rascunho G: Melancolia. In Edição Standard Brasileira das Obras Psicológicas Completas de Sigmund Freud (pp. 246-253). Rio de Janeiro: Imago. (Trabalho original publicado em 1895). 


\section{ARTIGOS}

Freud, S. (1996c). O ego e o id. In Edição Standard Brasileira das Obras Psicológicas Completas de Sigmund Freud (pp. 15-80). Rio de Janeiro: Imago. (Trabalho original publicado em 1923a).

Freud, S. (1996d). A organização genital infantil: uma interpolação na teoria da sexualidade. In Edição Standard Brasileira das Obras Psicológicas Completas de Sigmund Freud (pp. 155-161). Rio de Janeiro: Imago. (Trabalho original publicado em 1923b).

Freud, S. (1996e). Neurose e psicose. In Edição Standard Brasileira das Obras Psicológicas Completas de Sigmund Freud (pp. 167-171). Rio de Janeiro: Imago. (Trabalho original publicado em 1924).

Freud, S. (1996f). Fetichismo. In Edição Standard Brasileira das Obras Psicológicas Completas de Sigmund Freud (pp. 155-160). Rio de Janeiro: Imago. (Trabalho original publicado em 1927).

Freud, S. (1996g). A divisão do ego no processo de defesa. In Edição Standard Brasileira das Obras Psicológicas Completas de Sigmund Freud (pp. 153-170). Rio de Janeiro: Imago. (Trabalho original publicado em 1940a).

Freud, S. (1996h). Esboço de psicanálise. In Edição Standard Brasileira das Obras Psicológicas Completas de Sigmund Freud (pp. 293-296). Rio de Janeiro: Imago. (Trabalho original publicado em 1940b).

Freud, S. (2010a). Os instintos e seus destinos. In Obras Psicológicas Completas de Sigmund Freud (pp. 52-81). Rio de Janeiro: Companhia das Letras (Trabalho original publicado em 1915).

Freud, S. (2010b). Luto e melancolia. In Obras Psicológicas Completas de Sigmund Freud (pp. 171-194). Rio de Janeiro: Companhia das Letras. (Trabalho original publicado em 1917).

Lambotte, M.-C. (1997). O discurso melancólico: da fenomenologia à metapsicologia. Rio de Janeiro: Cia. de Freud.

Lacan, J. (1995). O seminário. Livro IV. A relação de objeto. Rio de Janeiro: Jorge Zahar. (Trabalho original publicado em 1956-1957).

Lacan, J. (2008). O seminário. Livro XVI. De um Outro ao outro. Rio de Janeiro: Jorge Zahar. (Trabalho original publicado em 1968-1969).

Marret, S. (2010). Le pas-tout sans le ravage. Conferência Antenne Clinique, Dijon, dezembro.

Miller, J.-A. et al. (2004). La psicose ordinária: la convención de Antibes. Buenos Aires: Paidós.

Miller, J.-A. (2005). El Otro que no existe y sus comitês de ética. Buenos Aires: Paidós. 


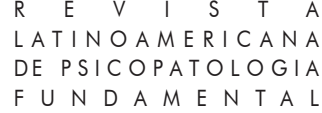

\section{Resumos}

(Psychopathology of eating disorders and their melancholic states)

The correlation between melancholic states and the psychopathology of eating disorders has been observed since the early days of psychoanalysis, and continues to be observed today. To update the research on the consequences of the melancholic position in the clinic of the anorexia, bulimia and obesity, we revisit the object relation metapsychology of these psychopathological states. We believe it can be of use to elucidating a possible phantasmal pattern in the symptomatic configurations of the different kinds of anorexia, bulimia and obesity.

Key words: Phantasm, melancholia, anorexia, bulimia, obesity

(Psychopathologie des troubles alimentaires et leurs états mélancoliques)

La corrélation entre les états mélancoliques et la psychopathologie des troubles alimentaires a été observée depuis les débuts de la psychanalyse et continue d'être étudiée aujourd 'hui. Pour mettre à jour la recherche sur les conséquences de la position mélancolique dans la clinique des anorexies, boulimies et obésités, nous revisitons la métapsychologie de la relation d'objet de ces états psychopathologiques. Nous

260 sommes convaincus qu'elle pourrait contribuer à l'élucidation d'une possible constante fantasmatique des configurations symptomatiques anorexiques, boulimiques et obèses.

Mots clés: Fantasme, mélancolie, anorexie, boulimie, obésité

(Psicopatología de los trastornos alimenticios y sus estados melancólicos)

La correlación entre los estados melancólicos y la psicopatología de los trastornos alimenticios fue observada desde los orígenes del psicoanálisis y sigue siendo verificada en los días de hoy. Para actualizar la investigación sobre las consecuencias de la posición melancólica en la clínica de las anorexias, bulimias y obesidades, revisamos la metapsicología de la relación de objeto de estos estados psicopatológicos. Creemos que esta investigación puede contribuir a la elucidación de una posible constante fantasmática en las configuraciones sintomáticas anoréxicas, bulímicas y obesas.

Palabras clave: Fantasma, melancolía, anorexia, bulimia, obesidad

(Essstörungspsychopathologie und ihre melancholischen Zustände)

Die Korrelation zwischen den melancholischen Zuständen und der Essstörungs - psycho-pathologie wurde seit den Anfängen der Psychoanalyse beobachtet und wird bis heute festgestellt. Um die Forschung über die Folgen der melancholischen Haltung in der Klinik der Anorexie, Bulimie und Adipositas zu aktualisieren, erkunden wir in diesem Artikel die Metapsychologie der Objektbeziehung dieser psychopathologischen 


\section{ARTIGOS}

Zustände. Zweck dieser Studie ist es, zur Aufklärung einer möglichen phantasmatischen Konstante in den symptomatischen Konfigurationen bei Anorexie, Bulimie und Adipositas beizutragen.

Schüsselwörter: Phantasma, Melancholie, Anorexie, Bulimie, Adipositas

\section{（饮食不良症背后的心理病症和忧郁状态）}

自从精神分析学产生的那时起，人们就注意到了忧郁症和饮食不良症之间 的某种联系, 但是这种联系目前仍然有待确认。为了研究忧郁症产生的后果, 比如厌食症 (anorexia), 暴食症 (bulimia) 和肥胖症, 在宏观心理学范围内, 作者查阅了讨论精神病症和饮食不良症之间的客观关系的文献。作者相信这样 的研究能够帮助专业人士解释那个一直环绕在厌食症, 贪食症和肥胖症病理学 之上的幽灵。

关键词：幽灵, 忧郁症, 厌食症, 暴食症, 肥胖症。

Citação/Citation: Oliveira, F. L. G. de, \& Santos, T. C. dos (2017, março). Psicopatologia dos transtornos alimentares e seus estados melancólicos. Revista Latinoamericana de Psicopatologia Fundamental, 20(2), 247-262. http://dx.doi.org/10.1590/1415-4714.2017v20n2p247.3

Editores do artigo/Editors: Profa. Dra. Ana Maria Rudge e Profa. Dra. Sonia Leite

Recebido/Received: 12.10.2016 / 10.12.2016 Aceito/Accepted: 15.12.2016 / 12.15.2016

Copyright: (C) 2009 Associação Universitária de Pesquisa em Psicopatologia Fundamental/ University Association for Research in Fundamental Psychopathology. Este é um artigo de livre acesso, que permite uso irrestrito, distribuição e reprodução em qualquer meio, desde que o autor e a fonte sejam citados / This is an open-access article, which permits unrestricted use, distribution, and reproduction in any medium, provided the original authors and sources are credited.

Financiamento/Funding: As autoras declaram não terem sido financiadas ou apoiadas / The authors have no support or funding to report.

Conflito de interesses/Conflict of interest: As autoras declaram que não há conflito de interesses / The authors have no conflict of interest to declare. 


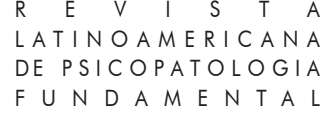

\section{Flávia Lana Garcia de Oliveira}

Doutoranda em Teoria Psicanalítica da Universidade Federal do Rio de Janeiro - UFRJ (Rio de Janeiro, RJ, Br), com estágio sanduíche na Universidade Paris 7 (Paris, Fr); Mestre em Teoria Psicanalítica pela Universidade Federal do Rio de Janeiro - UFRJ (Rio de Janeiro, RJ, Br); Especialização em Psicologia Clínica Institucional - Modalidade Residência Hospitalar pela Universidade do Estado do Rio de Janeiro - UERJ (Rio de Janeiro, RJ, Br); Membro adjunto do Instituto Sephora de Ensino e Pesquisa de Orientação Lacaniana (ISEPOL); Bolsista da CAPES.

Rua Santos Titara, 17/201 - Méier

20735-240 Rio de Janeiro, RJ, Br.

flavialanago@gmail.com

\section{Tania Coelho dos Santos}

Pós-Doutorado no Département de Psychanalyse de Paris VIII (Paris, França); Professora Associada IV do PPG em Teoria Psicanalítica da Universidade Federal do Rio de Janeiro - UFRJ (Rio de Janeiro, RJ, Br); Membro da Associação Universitária de Pesquisa em Psicopatologia Fundamental - AUPPF (São Paulo, SP, Br); Psicanalista; Membro da École de la Cause Freudienne; Membro da Escola Brasileira de Psicanálise (Rio de Janeiro, RJ, $\mathrm{Br}$ ); Membro da Associação Mundial de Psicanálise; Pesquisadora bolsista nível $1 \mathrm{C}$ do $\mathrm{CNPq}$ (Brasília, DF); Presidente do Instituto Sephora de Ensino e Pesquisa de Orientação Lacaniana (Rio de Janeiro, RJ, Br); Editora de aSEPHallus Revista de Orientação lacaniana (Rio de 262 Janeiro, RJ, Br).

Rua Visconde de Pirajá, 318/608 - Ipanema

22410-000 Rio de Janeiro, RJ, Br.

taniacs@openlink.com.br

This is an open-access article, which permits unrestricted use, distribution, and reproduction in any medium for non-commercial purposes provided the original authors and sources are credited. 